„Etnografia Polska”, t. LXIV, 2020, z. 1-2

PL ISSN 0071-1861; e-ISSN: 2719-6534

DOI: $10.23858 / \mathrm{EP} 64.2020 .005$

CC BY 4.0

JUSTYNA STRACZUK

Institute of Philosophy and Sociology, Polish Academy of Sciences, Warsaw

\title{
"I STILL REMEMBER THIS TASTE". SENSES AND EMOTIONS IN PERCEIVING CULTURAL CHANGE
}

In this article I deal with the memory of taste as it is expressed in personal narratives about the past by various generations of people living in Poland. Memory studies typically pay little attention to the role of the senses. This is partially due to the belief that the senses are too intimate and elusive to become a research area. Nevertheless, although sensory impressions are a very fleeting experience, at the same time they make memories tangible and expressive. By analyzing statements about remembered foods and foodways from the past, I want to find out what role the senses, especially the sense of taste, play in the process of remembering and what makes them such suggestive and powerful tools in illustrating the past. I would also like to look at how the memory of sensory experiences is subject to certain norms of remembering and evaluating social changes, and how it expresses attitudes towards the present.

\section{BACKGROUND}

In his seminal work, Halbwachs (1980) argued that individual memory is created in a specific social environment whose ways of perceiving and understanding the world we always refer to when we think of our experience. When recollecting the past, an individual - he wrote - always adopts the view point of his or her group (Halbwachs 1980, 23). On the other hand, group memory exists only insofar as it crystallizes in the individual memory of its members. Halbwachs's successors demarcate these two registers of community remembrance differently - on an individual and collective level - pointing to distinct modes of recollecting, recording, and storing. For example, Jan Assmann makes a distinction between cultural memory - deliberately shaped by collective entities, institutionalized, conveying a formalized body of information expressed in fixed and entrenched forms, and communicative memory - which occurs spontaneously as a result of daily interactions between people, and which refers to a past bounded by the lives of the people remembering it. That same event - Assmann writes - may become an object of both cultural and communicative memory, but the mode and outcomes of remembering will be different in each case (Assmann, 2008, 109-118). On the other hand, Jeffrey Olick differentiates between 
collective memory, existing as a set of symbols, media, institutions, and social practices used in building and representing the common past, and collected memory, which develops individually thanks to the culture-specific patterns and norms absorbed by an individual in the course of their socialization. Insofar as the level of collective memory - he writes - serves to develop so-called grand narratives, which are the building blocks of collective identities, the level of collected memory, more spontaneous and built on small narratives, acts as counterweight to the official, institutionalized type of memory (Olick 1999, 333-348).

When thinking about social contexts of individual memory, researchers tend to overlook the individual human body. In works analyzing how the social aspects merge with the individual ones in the process of remembering, they mainly refer to cognitive memory, which is expressed in narratives, recorded or preserved in the form of artifacts (Assmann 2008; Olick 1999). However, there exists yet another register of social memory, which nevertheless rarely becomes a subject of memory studies. It is this type of memory: nondeclarative, habitual, conveyed by the human body and rarely expressed in narrative forms - that Paul Connerton (1989) writes about in his seminal work How Societies Remember. This kind of memory is articulated through repetitive, routinized bodily practices, specific gestures, postures, and techniques. Habitual memory is simply what is being embodied, occurring, and arising from the repetitiveness of the specific bodily practices one adopts in the process of functioning in the cultural and social world. As Connerton writes: "In the habitual memory the past is, as it were, sedimented in the body" (1989, p. 72), unmediated by mental representations. The social character of such memory lies, above all, in the social formatting of the subject who keeps it.

Connerton distinguishes between two types of commemorative practices: the practices of recording and preserving memory in tangible forms, and the practices of embodiment. It is the latter that draws his closest attention. He describes ceremonies, characteristics, and techniques involving the body as a specific means of recreating the past. Referring to, among others, Elias, he shows how embodiment practices become a record of a historical process by which social rules, norms, and standards of behavior are internalized. Through daily, mostly non-reflective practices, the body tunes into the socially adopted ways of handling it. It also adopts characteristics specific to a given group. "A predisposition formed through the frequent repetition of a number of specific acts" - states Connerton - "is an intimate and fundamental part of ourselves" (1989, p. 94). Such a deep level of internalization also refers to physical sensations. Our notions of what we like and feel, what we find pleasant or abhorrent, also have a social character as they result from social learning. Connerton writes in this context about Bourdieu's concept of habitus, understood as enduring dispositions of the body attained in the process of socialization, existing outside the realm of introspection or conscious control. Bourdieu (1984) asserted that socially developed and reinforced bodily practices shape not just our behavior, but also our sensory predilections and perceptions. Through analyzing the peculiar interplay between the seemingly inborn character of sensory sensitivity and its inherently 
social origin, he shows how it serves to naturalize and validate social hierarchies and the consequent inequalities.

This deep level of the embodiment of cultural norms, values, and hierarchies is of particular interest to researchers in the field of the anthropology of the senses. They oppose the widely held conviction that sensory experiences predate culture. Sensations, they assert, are not only bodily, but also cultural acts, and the senses themselves are imbued with cultural meanings. In their studies exploring various cultural and historical contexts, Constance Classen $(1999,2010)$ and David Howes $(2010,2013)$ demonstrate the key role culture plays in shaping our sensations and delineating their interpretive boundaries, norms, and patterns. Merely through distinguishing some senses and sedating others, and through establishing their hierarchies, culture develops a range of sensory registers that arrange themselves into sensoria, perceptual apparatus, ways of sensing, through which the members of a given society make sense of the world. These sensory patterns are historical and political formations. As such, the senses play an important normative role, acting as a channel for transmitting cultural values and as an effective tool for establishing social relations. Senses are thus not only culturally and socially shaped, as they are also far from being semantically neutral. Michael Herzfeld (2011), describing how bodily sensations and cultural values interrelate in various ways, suggests that not only the diversity of such interdependencies be studied, but also their consequences for the wide range of relations and social acts.

One of the possible areas of research is the issue of memory and the role the senses play in its recalling. In his book about the historical memory of inhabitants of a Cretan town, Herzfeld (1991) indicates that senses have a specific evocative function in recalling the past. Describing the 'smellscape' of the town, which included local stories, as well as individual recollections, he highlighted the role these sensory experiences played in creating strong emotional associations between the past and the present. Similarly, Nadia Serematakis (1993), writes of the distinctly evocative and nostalgic dimension of sensory memory. In her essay on longing for the flavour of a forgotten variety of peach once cultivated in her native Greece, the author shows how taste becomes a personal narrative about change, a tale of a lost world and an unintentional judgement about the present, which no longer tastes like before. Tracing the relationships between memory, senses, materiality, and local epistemologies, Serematakis notices that the sensory transformations are usually imperceptible on the daily life level, and only through their recollection it is possible to grasp the past with such distinctly affective power.

This peculiar affective function of the senses, when it comes to remembering, is also a subject pursued by psychologists, who, armed with knowledge from the field of neurology, explain the strong relationship between memory, senses, and emotions, by how closely together the organs responsible for these functions are located in the human brain. In recalling memories, a unique emotional power is attributed to the senses of smell and taste, due to the fact that compared with other senses, these senses are localized in closer proximity to the amygdala, which plays a key role in 
processing emotions. Because of this proximity, neuron connections are shorter and therefore able to trigger emotional reactions much faster and more easily than in case of senses of sight, hearing, and touch (van Campen 2014). Notwithstanding the fact that psychologists tend to separate memory processes from their social and cultural context, the works of Jeffrey Prager (1998) are worthy of note. He argues that the process of reclaiming the past is equally controlled by two factors: the embodiedness of this process through emotions and senses and its embeddedness in the social context. The past becomes recorded in bodily sensations and emotions, and the deeper the recollection is embodied, the stronger its subjective meaning and the bigger its potential for social sharing and its resistance to change.

On the other hand, David Sutton, the author of Remembrance of Repast (2001), believes that the peculiar power to remember inherent in our senses arises from the process of synesthesia, of stimulating and merging various sensory registers: taste, smell, sight, touch, and hearing. Taste and smell belong to the most ephemeral, but also the most emotive and nostalgic feelings. Because these sensations are ephemeral and difficult to verbalize, in our memories they usually evoke everything that surrounded them, that became linked to them metonymically: space, time, objects, persons, situations, and moods. As Sutton (2010) writes - sensations always get crossed with the particular social and cultural context, thereby becoming virtual archetypal symbols.

John Holtzman (2006) presents yet another argument about the power of taste memory in his article Food and Memory. He argues that the peculiarly symbolic power of food in relation to remembering arises from its dual character: food relates directly to our materiality, but at the same time is an integral part of our social relations. Therefore, food is located at the juncture of the individual and social, the intimate and public, and the biological and cultural. Holtzman points out to several social spheres where this capacity of food to attain symbolic meaning becomes particularly salient. These spheres include various forms of group identity practised through eating: "traditional", "ethnic" or "national" dishes. These practices strengthen the sense of not only spiritual, but also material and bodily collectiveness. The memory of taste and its affective connotations are also frequently analyzed in situations of migration, such as the Greek diaspora in the USA described by David Sutton (2001), who demonstrates how people experience a fragmentation of their lives, because they lack access to a complete sensory world of their country of origin. Food memories then become a way to recall that past, and an effort to revive them in the new material environment. This "gustatory nostalgia" - as Holtzman calls it - may also refer to times and places never experienced, becoming a handy tool for invented traditions or fictional identities (Holtzman 2006, p. 368).

In all of the above mentioned studies on the role of the senses in the process of remembering it follows that the special evocative quality of the sensory memory arises from its affectiveness, and from being easily connected with the social context. I would thus like to turn now to the specific historical and cultural context of post-war taste memories in order to analyze how they are individually and collectively shaped by different representatives of Poland's people. 


\section{THE RESEARCH MATERIAL AND METHODS}

The research material is comprised of in-depth interviews conducted in 2014 with 67 people living in Poland who exhibit diverse socio-demographic characteristics in terms of age, sex, place of residence, and education. The selection of the respondents was purposive, i.e., we tried to form a similar sample to the representative one used in the survey research that entailed the first stage of the series of projects on food and foodways in Poland ${ }^{1}$. The interviews lasted from 1 to 3 hours and focused on eating issues, pertaining to shopping, dietary preferences, daily practices, changing eating habits, attitudes toward traditional and "new" cuisine, diets, healthy eating, and moral aspects of eating ${ }^{2}$. In this article I analyze only part of the material pertaining to taste and the senses, memories and emotions.

As researchers, we do not have access to the embodied sensory experience of our interlocutors and their habitual memory. We can only reach them in a way mediated by narratives that are already cognitively developed. The sensory experience is already verbalized, systematized, and, to a significant degree, disembodied, becoming an object of thought, interpretation, and intersubjective exchange. However, the variety of experiences that emerge from these narratives reveal various modes of sensory remembrance with its significant emotional charge, and expose the social and cultural role of the senses in the process of recollecting the past.

\section{BIOGRAPHICAL MEMORY OF FOOD EVENTS}

In all the conversations about the memories of tastes, the respondents attached the strongest emotions to their childhood recollections. Often, despite the fact that many years have passed since the actual experiences, these memories are clear and vivid. The memory of the oldest generation of respondents, born before World War II, reaches beyond the period of socialism to the occupation of Poland by Nazi Germany. The perspective of this wartime generation is often charged with the memory of hardship, deprivation, as well as frequent hunger. A retired teacher, reminiscing on his forced labour in Nazi Germany, says:

I harrowed (the field) with one horse when I was a 12-or 13-year-old lad. I harrowed, and far beyond the village there were large fields, close to the sugar refinery, about $6 \mathrm{~km}$ from the place where I lived. [...] And we had a break for some breakfast. The Germans were eating, but I had no food so I just sat there. And one German brought me..., even now I find it hard to talk about this... [very emotional,

teary] some bread with an egg. The egg, hard boiled and placed together [with bread]. $\underline{\text { So this taste }}$

\footnotetext{
${ }_{1}$ The interviews were conducted as a qualitative part of the research project Patterns of Eating and Social Structure, directed by Henryk Domański, whose main part focused on quantitative research of the representative sample of 2000 inhabitants of Poland. The project was carried out in 2012-2016 with funding from the National Centre for the Sciences (2011/03/B/HS6/03983).

${ }^{2}$ Interviews were recorded and then verbatim transcribed. I used Maxqda software to code the data and to facilitate further analysis.
} 
I still (remember) today... [emphasis mine] I often went hungry, they would be eating and I would be walking behind that horse. I could barely walk, but I did. [1/M/1945/S/M $]^{3}$

The taste of an egg sandwich is metonymically connected with the entire context of war misery that the young man had to endure, being separated from his family, working beyond his strength and being underfed and lonely. The emotional gravity of this recollection, which produces deep feelings and tears 70 years after the experience took place, makes it especially compelling. This event is significant to the respondent's identity, as it permeates his vision of self and his relationship with the world ("people differ", "I have never made a fuss" - he says in the latter part of his account). These memories show how clearly sensory experience from distant childhood can be evoked, as long as it is emotionally charged and has a significant meaning for the individual story. This enduring and embodied memory of taste is accompanied by detailed recollection of the actual topography and circumstances. The image from the past is clear, and the old experience, through its physical repeatedness ("this taste until today") is still, to a certain extent, present.

Memories of much younger people involving food flavours from childhood years are often equally strong and emotionally laden. A 30 year-old electrician, who served a prison sentence, and who was brought up by his grandmother, when asked to explain why cabbage stew (bigos) is his favourite dish from childhood years, responds:

Cabbage stew (bigos) was the only dish that my father bought me when he took me for our one and only trip. So... I remember that stew, and it was also such a day when I remember this fatherly care, because it was a pub for generally intoxicated people and ... bigos was one of the dishes served there. So I still remember that cabbage stew today, that taste. And I also remember that my father was very protective of me there and so on. He protected me so nobody would bother me. And it is this memory which has meant a lot to me - then and now. Because this was one of the very few conversations I have ever had with my Dad. So that's why I remember it. [56/M/1965/S/BC]

The memory of taste here relates directly to a deeply internalized experience of meeting with a rarely seen father, with the need for his closeness and loving care. Similarly to the narrative of the retired teacher, the recollection of this particular day, the circumstances, and place is depicted very clearly. The memory of how the dish eaten then tasted not only invokes specific emotions: the feeling of security and being cared for by one's father, but also replays the entire past context of pubs in which men drank alcohol, popular during socialist times. The memory of a favourite dish, powered by emotions and by a repeated sensory experience, is a crucial, embodied, and subjectively significant aspect of selfhood. The taste of bigos becomes an important element of the story of self, a biographical narrative about childhood deprivation and unfulfilled emotional needs.

${ }^{3}$ In brackets: information about the cited respondents [Interview NR/ Sex: (Male, Female)/ Age: (born before 1945, 1965, 1985)/ Education: (Elementary, Vocational, Secondary, Higher)/ Place of residence: (Metropolis over 500,000 inhabitants, Big City 50,000 - 500,000, Small City below 50,000, Village)]. 
Let's take a look at another example. An academic who grew up in the countryside, when pondering his fondness of meat, reminisces on the domestic pig-slaughtering ritual (quite common during the economic crisis of the socialist era, when one had to buy meat on the black market) in which he partook with his father as a child. This was quite a common activity during the economic crisis of the socialist era in the late 1970s and 1980s. Due to market shortages, the illegal slaughter of livestock at domestic farms was one of the main ways to obtain meat, which was then distributed through family and acquaintance networks between rural and urban residents.

I always liked to watch my father dismember meat, this was always something magical. [...] I remember this situation when my Dad, the whole pig was dismembered, Dad was already mincing the meat for sausages or was cutting the meat up for mincing. So I came into the garage where this was happening, and there was this smell... almost... like... [he is thinking]. Well, I don't know, I don't want to say that this was a mystical experience, but the smell, all of this, it was... I felt compelled to... cut off a piece of that raw meat and try it. This was the last time I ever tasted raw meat. But simply, I don't know what it was then, I don't know. But this is probably my most intimate childhood memory; when it comes to food, this is it. [59/M/1965/H/BC]

The main theme in this recollection is that of being intoxicated with the smell of a freshly killed animal, which triggers in the respondent an 'atavistic' impulse to try a piece of raw meat. He finds this experience incomprehensible, but at the same time, powerful and captivating. This intimate, as the respondent refers to it, childhood recollection, not only provides a justification for his carnivorous tastes, but also embodies meanings relating to masculinity and vitality. The formative experience is important: for the son, participating with his father in the killing ritual becomes an initiation to an adult, manly life. This is probably why the memory of this event is so powerful and emotional.

However, not only dramatic memories of individual experiences are so effectively and faithfully remembered. The taste, related to situations of emotional comfort, where feelings of safety and satisfaction prevail, also feature in recollections of common everyday situations. One of the respondents talks about how in her mind taste has become fused with the process of reading books as a child and with the related aura of homely relaxation.

Childhood... Oh. I remember..., Yes, I mean, there was definitely pork loin. In a way I associate it with reading books, because, simply, I somehow still remember these tastes, they somehow are... I have memorized, for instance, how I got sick once and couldn't go to school, and my parents would leave roast pork sandwiches for me, and I would just sit back and read books. So I have these mental associations: simply eating and reading, and plum preserves too, and also... and, yes, that was when I was reading the Three musketeers. The plum preserve, on the other hand, I associate with Sherlock Holmes, I have two memories of this, I remember it so well... [18/F/1985/H/M]

Unlike the previously quoted male memories of consumption spaces, female food memories are very often associated with cooking, learning culinary arts from mother or grandmother. Memory is located not only in taste, but in manual skills, in the repetition of the same activities practiced under the supervision of the experienced 
relative. The memory of this woman is reified, embodied in the cooked and consumed dishes, and thereby becomes even more tangible and alive.

I remember at first that I made dumplings with my great-grandmother, that I cut circles with a glass for these dumplings, that I put in the stuffing, that my grandmother made pasta herself and then dried it herself on the radiator in paper bags [...] I remember when my great-grandmother died and I was already in college then, she was 89 years old and when she died, we ate pancakes at the wake, which she had fried herself before her death. And it was a very special experience. That she managed to fry pancakes with meat and she always had such a habit that she cooked broth and then used this meat from this broth for various other dishes. I still do it that way, myself. [17/F/1985/H/M]

Childhood memories of taste are related to specific emotions and actual psychological circumstances: suffering, loneliness, lack of care, but also the feeling of security and parental care. Moreover, almost always these memories are linked to a nurturer. The cabbage stew is reminiscent of the day when the boy was cared for by his father. The egg sandwich becomes a metonym of the good German's compassion. The taste of raw meat recalls the pig-slaughtering ritual. Broth, dumplings, and pancakes are associated directly with the deceased grandmother. The memory of food becomes associated not only with the days gone by but also with people, places, and situations. It becomes directly conflated with individual activities and objects, refers to a certain material context, to crumbs of the reality of the past, to common practices at the time, such as family pig slaughtering, home-made preserves, or dumplings, places such as the then typical eateries where mainly alcohol was consumed. In this social context, it becomes preserved, intensified with powerful emotions, delineated, and tangible. In all probability, the original sensory experience wouldn't be so significant, if it weren't embedded in the narrative that is no longer just a reminiscence of the taste itself but is reinterpreted as a tale of personal and social meanings of taste. The memory of tastes that relates to childhood episodes is crucial in self-insight, influencing how the respondents see themselves, not only then, but also now. The enduring impressions of taste, their lasting "memories to this day", form an axis that links the past with the present, and the medium transmitting this memory is the remembering human body. The taste of the past is told, but it is deeply rooted in the body, which remembers nondiscursively "to this day".

\section{MYTHICAL MEMORY OF COMMON TASTES}

Individual biographical food memories show, above all, a huge emotional charge, along with importance in shaping identity and the ability to recall social contexts. Apart from individual memories of events, where taste is imbued with various personal connotations, our conversations also reveal food memories that form part of broader social experience, relevant to the times and situations. They are repetitive recollections clothed in particular narrative patterns that employ conventionalized means of expression in which the social framework of remembering and creating 
memory narratives is revealed with particular force. These memories include descriptions of home cuisine, dishes served in everyday situations, that were the norm in many households.

For much of the older generation the recollections of food eaten in childhood or later during their youthful years are connected with the cuisine typical of the peasant style of cookery ${ }^{4}$. These people remember a limited, monotonous diet, an unsophisticated cuisine suited to the agrarian lifestyle, where there is no time for cooking. Accounts of eating this type of food are automatically integrated into the narratives about old rural day-to-day life, about poverty, hardship, and exhausting work in the fields. Here, food is inseparable from the peasant lifestyle. When respondents say "we used to eat like this", at the same time they tell us: "we used to live like this".

However, amongst these realistic descriptions of rural poverty and Spartan living conditions, where food is simple and always in short supply, threads of nostalgic memory of taste also appear. They primarily relate to the festive, exclusive cuisine, which is linked to special and socially significant situations. Such tales include descriptions of home bread baking. Here, the taste is particularly interlinked with family living. Making bread at home is a unique social institution in which the communal life of the family is centre-stage.

Grandma baked the bread, took it out of the oven, [...] On this big table, she put the baking trays with the bread loaves there. And the smell of it was overwhelming, Jesus, I wanted to taste that bread so bad. [...] And she gave me some of this bread, but only later, when grandpa and my uncle had come back home from the fields, the bread was already cool, so only then did she cut it up and put her own butter on it. I didn't want anything else, anything, there was also quark cheese there, but [I wanted] only the bread and that butter. That taste, that bread [eaten] then was the tastiest, and I remember it to this day. [49/F/1965/H/SC]

The flavour and aroma of freshly baked bread is a tale with a repetitive narrative pattern that stems from the order of the consecutive stages of a domestic ritual. Typically, it involves a description of getting excited, when the mother or grandmother would take the bread out of the oven, a recollection of the house filled with the aroma of bread, the impatient waiting for the loaves to cool down, and then the family gathering around it, dividing the loaf and finally, joining in its consumption. Thus, the uniqueness of the taste of freshly baked bread is directly linked to familial unity. Our respondents' accounts often conclude with the statement: that taste can never be repeated. Modern sourdough bread no longer tastes like that bread from the past. As one of the respondents puts it: "the taste seems perfect, but it is no longer the same". Indeed, that old taste cannot be recreated, just as one cannot restore the traditional rural familial community grouped around the production and consumption of "their own" food. Thus, even though the taste of bread is to a large degree influenced by the changing methods of flour production and baking, this opinion is mainly informed by the past social context, which was unique and is therefore unrepeatable.

${ }^{4}$ Until the mid-1960s, the rural population comprised the majority of the total population of Poland (Sto lat... 2018). 
Nostalgic childhood memories of people who were children in the 1970s and 1980s are directly linked to Grandma, who is a special figure in Polish culture: she centres her life around her grandchildren, she nurtures, overfeeds, and spoils them, and makes them feel secure and loved. The memory of the taste of Grandma's cooking is placed within this paradigm of happy pastoral childhood. The food remembered, such as the baked loaves of bread, is incredibly tasty, incomparable to anything else, unrepeatable, because one was a child then, experiencing the world in a childlike manner, perceiving it mainly through one's senses.

I remember the most how Grandma made scrambled eggs. This was the Grandma who had her own farm and she made everything from her own flour and milk. It is such a taste that... [...] Well, it's hard to describe really, hard to put into words, but it was incredibly tasty and I have never ever eaten scrambled eggs so tasty. [...] And I know that I will never taste anything like that again. [48/F/1985/H/V]

I actually remember many culinary things from my Grandma, the things that I liked the taste of [...] Well, you remember such things from your childhood, and these memories certainly stay with you. When I have the opportunity, I even make some of these [dishes] myself from time to time. They probably don't taste the same as before, though they are very good - or, maybe not, maybe they do taste the same - but it was another time, when one was young and ate these dishes then... [26/M/1985/V/V]

The memory of the taste of home-baked bread and meals cooked by Grandma, is inseparably connected with time, people, and situations that one cannot return to. These are individual biographical recollections but dressed in conventional forms, specific formulas, and figures of remembering. They adapt to cultural norms: the taste of home-made bread or grandma's cuisine must be unique. The uniqueness of taste becomes a story of irreversible loss of one's entire social and cultural world. The nostalgic remembrance of home tastes and flavours that have been lost forever, acts as a medium for transmitting an important cultural message, a mythical tale about happy childhood and idyllic rural life.

\section{GENERATIONAL MEMORY OF SOCIALIST TASTES}

As we know from Halbwachs' work (1980), individual memory is always dialogic: we remember and we think about the past through shared structures of understanding and talking. Such communities of shared narratives are often formed by generations living in similar historical circumstances and comparable cultural and social backgrounds. The notion of generation plays an important role in memory research. Pierre Nora (1996) argued that each generation is a product of memory due to the formative character of key historic events that are shared and that have shaped a culture peculiar to that generation. The specific and unique nature of the experiences of each generation makes its collective memory distinct in its character. According to Mannheim (1952), it is the period of late adolescence and early adulthood that is the most formative stage of life in each generation. This is due to fresh, youthful perception and the highly emotional nature of experiencing life that is typical at 
this stage. Thus, experiences from the person's youth become a foundation for their developing worldview.

In regard to memory, it has also been noted that intergenerational differences may stem from similar sensory experiences, as well as from similar modes of interpreting and representing these experiences. They become intersubjective by way of circulating stories, conventions, and figures of memory, and by being automatically included in various individual narratives, thus defining social frameworks for remembering. We may refer to this as a process whereby particular conventions of remembering created from individual experiences are incorporated into narrative patterns shared within each generation.

The memory of respondents born before $1965^{5}$ is predominantly of the nostalgic type. Unpleasant aspects of life, such as the daily struggle to snatch foodstuffs or the difficult task of 'cooking from nothing', appear in their accounts relatively rarely. Their memories are usually about exceptional, unique flavours that are linked to distinct positive activities. This is exemplified by the instance of private production of cured meats from the animals slaughtered at family farms in times of meat shortages. Meat was a very political foodstuff during the whole socialist period. Its abundance in the marketplace was a sign of the fulfillment of the government's promises for the welfare of working people. For this reason, the relative prosperity of the early Gierek era (1970-1980) is associated primarily with an abundance of tasty cold cuts ('ham like in Gierek times'). The economic crisis at the end of this era, rising food prices, and the shortages of meat on the market were direct causes of social discontent and protests (Kochanowski 2010). At the same time, people's resourcefulness in obtaining meat from outside the official market, the success of which was based mainly on the system of acquaintances and family ties, made meat not only an object of desire, but also an element of maintaining strong social relationships (StańczakWiślicz 2014, Brzostek 2010). That is why the taste of these meats is indeed unrepeatable, becoming a generational experience of communal ingenuity and solidarity, of strong community bonds reinforced by the exchange and circulation of goods that were difficult to obtain.

A 60-year old unemployed man, a former musician, when asked about food from the socialist era, states that the food was incomparably tastier:

Perhaps I could give you an example of the cured meats, ham. The only type of ham available was smoked, with bone, and had to be cooked. These were fantastic hams. Nowadays you won't be able to eat like 30 years ago. Or when I went to the country, people there were making and smoking [ham] on their own. Lovely. This is real ham. You can't buy such hams in the shops now. I haven't eaten such ham [since]. [3/M/1965/S/M]

A middle-aged woman reminisces in a similarly sentimental tone:

${ }^{5}$ It is difficult to draw a sharp line between generations when it comes to year of birth. For the purposes of this work, we treat 1965 as the border for the generation whose first childhood memories date back to the times of Edward Gierek's rule (1970-1980), and who entered their adult life in the new political system that began in 1989. 
The pork loin. When I remember the taste of [roasted] pork loin at Christmas, I simply..., this was unforgettable, really, I haven't eaten such pork loin since. With all due respect, so to speak, to all these more common cured meat varieties, and so on. [60/F/1965/V/BC]

The flavours of meat and its cured products have become an important part of the collective memory pertaining to everyday life in the PRL [the Polish People's Republic], even one of its most characteristic distinguishing features. The nostalgia for "ham like from the Gierek era" resurfacing today does not just convey the unique nature of that particular taste, but also carries a positive image of that era, when resourcefulness and cooperation enabled people to step outside the oppressive system and ensure a reasonable standard of living for themselves. Memories of the taste of homemade cured meats act as a parable about the community life and social resourcefulness typical of the era.

In the stories told by the older generation the theme of the irreversible loss of a particular taste often reappears. It is not just longing for a bygone era, but also an evaluation of present times, when consumers no longer have much control over the system of food production and are not sure about the origin and content of food products. The memory of how food used to taste, of the flavours one cannot find anymore, serves as a metaphor for alienation and becoming lost, for one's inability to fully adjust to the new reality. This kind of nostalgia for socialist tastes is often described in other postsocialist contexts (Caldwell 2003; Dunn 2008; Jung 2019; Ries 2009). It is about longing for the familiar and safe world of sensations that is lost forever. From this perspective, modern "capitalist" products are devoid of the sensory appeal of the old foodstuffs; they are artificial, inauthentic, and have no flavour. This applies not only to new production and sales systems, but also to nature itself, which now produces only tasteless fruit. As one of the respondents says:

Even in those soups the vegetables tasted differently. As I say: we'd go to the forest, we'd gather some wild mushrooms - mushroom soup or something. It really did have the aroma. And now, what: you have to go out and then you have to buy [the vegetables]. But it is not the same anymore. [3/M/1965/S/M]

Retired sisters, reminiscing about the taste of fruit from the past, compare it to that of the modern "fake" produce.

DK: Vegetables, fruit. Or apples. There are no longer varieties like those old ones, no. [...] So there was this Reine Claude plum, green, yellow-green, big. It seems this is also a Reine Claude plum, but it is not the same. Apples were also different then, I don't know the name of them, they were so beautiful.

TK: [interrupts and talks over]: Each apple cultivar was simply full of good flavour. The true taste of an apple, of a particular variety. Because nowadays you can buy them at a market... Cortland, or some Lobo, or some other different varieties, but in terms of flavour, they are all the same, they taste like potatoes. [49/F/1965/H/SC]

Indeed, the blandness of modern mass produced foodstuffs is not only the result of changing tastes, but also an effect of broader socio-economic processes: it takes longer for food to get from the field to the table; there is a lack of control over the production system; food manufacturers apply immoral practices; consumer involve- 
ment in effecting change is lacking. Thus, changes in flavour or the lack of flavour may be interpreted as our respondents' direct evaluation of the changes to contemporary lifestyles and the ways of functioning in the world.

Younger people describe the past differently. The common experience of this group relates to the shortages of children's favourite foodstuffs: chocolate, sweets, and exotic fruit. The centrally planned and managed system of goods distribution made the supplies of these desirable foodstuffs available in the weeks before important holidays. Christmas baskets for children distributed at workplaces were also popular. The festive times have therefore become fused with the aroma of oranges and the taste of chocolate. The seasonality of consumption, when it comes to these desirable products, is firmly embedded in the memory of the younger generation. The flavours of these delicacies have become intrinsically fused with the notions of exclusivity and uniqueness.

Oranges, bananas, ham... Here there are really, these smells. Not the dumplings, not the bigos, not the fish, but simply this. This was very special... truly [60/F/1965/V/BC]

In regard to everyday food, inasmuch as Grandma's cooking is remembered with fondness, the cuisine of mothers - overworked women, burdened with both paid and domestic work - is not that sentimental. The shortage of time and leisure was exacerbated by shortages of goods, by the constant struggle to obtain available products, and the lack of choice and poor quality of the goods available. Cooking for the family during times of crisis and scarcity was regarded by many women as a curse, as the children of the era remember:

My Mum hated cooking. She used to prepare dinner/meals for the whole week ahead. Generally her aim was to make sure everybody was well-fed and ate a lot of meat - typical of the communism years, wasn't it? Having a lot of meat meant things were OK - we live well, we eat meat. But she was never really interested in making the food taste good. [16/F/1985/H/SC]

My Mum was never really fond of cooking. Food at home was terrible. Awful. I used to eat tinned food. I would come back from school and open the can of flageolet beans. I remember it to this day. So the taste of my childhood is either the can of sweetened condensed milk, one teaspoon when I was reading a book, or the flageolet beans the following day. And those are the flavours of my childhood, but I am not trying to seek them out. [37/F/1985/H/V]

The cuisine of the past, Mum's cooking, even when the mother was more eager, persistent, and confident to cook, is also remembered by many members of the younger generation as unhealthy, fatty, and harmful, so they reject it today. Today, they consider the dishes that they used to eat daily throughout their childhood and adolescence years to be unhealthy and harmful. Aversion to the old cuisine is somatized, expressed by body reactions:

I mean, I prefer the food of today, I feel better when I've eaten something lighter, without all this fat, because I remember when Mum was pouring this fat with pieces of crackling on the boiled potatoes, this is how it was. So now, when I prepare something light for myself, I feel much better. I mean mainly these feelings, like they are felt through my stomach. [54/M/1965/H/BC] 
This is not the kind of taste anyone misses. Rather, the respondents describe Mum's style of cooking as monotonous, repetitive, boring, but above all, as unwholesome. In their accounts, the food of the past is juxtaposed with the contemporary diet, which is diverse, healthy, and well-planned. Memories of the taste of home cuisine from the past are also shaped by the negative attitude to the traditional view of food as fuel for the body. The new, distinctive functions of taste that have become an important aspect of the modern middle-class lifestyle make the old perception of food (which gave paramountcy to the functional category of nutrients satisfying the body's energy needs) lose its significance. The separation from the traditional style of eating, typical of the socialist period, so characteristic especially for the younger generation of the urban middle class, can therefore be treated as an aspirational action aimed at strengthening one's social position and lifestyle, in which culinary taste plays an important role.

The PRL period acts as a common reservoir of memories, although it tends to be evaluated differently. The older generation reminisces on the flavours of home cookery, home grown food, and do-it-yourself products in a nostalgic way. References to 'this taste' are imbued with connotations of community and family living, work ethics, familiarity and resourcefulness. It is important that these recollections rather sporadically involve shortages of goods, 'erzatz' products (when the original products, like chocolate or coffee, were unavailable), the monotony of flavours and meals, and the dullness arising from the limited choice of foodstuffs. In their food memories, the PRL generation of adults forgets the negative aspects of market shortages. However, the younger generation is somewhat ambivalent about them. On the one hand, they fondly remember Grandma's simple country cooking; on the other, they often complain about the traditional, plain, boring and unhealthy cuisine of their parents.

These different experiences and memories also prompt a variety of judgements and opinions in regard to the modern times. Many older people are somewhat lost in the new free market system, hence their tendency to nostalgically hark back to the old system, in which they felt safe and at home. The old flavours were different and unrepeatable not only because food was made with different techniques and was less processed. The memory of good tastes also involves longing for those bygone days. For the younger generation, well established in the modern era, those old, dull times do not convey positive emotions, and this is to some extent the reason why the traditional style of cooking from that era is no longer highly regarded.

\section{CONCLUSIONS}

The memory of taste takes various forms and fulfills a range of roles in the process of recalling the past. Individual remembrance narratives relating to embodied memory are always situated within a particular material and mental space characteristic of a wider society. Specific remembered events relating to tastes from the past always occur in a specific social and material setting, among actual people and objects that 
jointly create this space. The memory of taste emerging therefrom is at once deeply personal and social, operating within the cultural environment. Likewise, through the act of sharing this experience in a verbalized, narrative form, the individual memory becomes intersubjective and socially formatted. The boundaries between individual and collective memory are fluid and can be crossed, thus mutually reinforcing both memory registers.

In autobiographical accounts of particular food events, the memory of taste, and especially the nostalgic recollections of flavours from one's childhood, have powerful emotive qualities that render these however distant memories still very vivid and emotive today. In particular, it is the significant components of one's life story, still emotionally potent, that are remembered. This emotional intensity also influences how one interprets and what significance one attributes to the remembered events. The embodied taste, when related to an actual incident from the past, strengthens not only the power of the experience itself, but also its significance as part of a selfcreated narrative about oneself. An important episode from one's childhood, strengthened by the physicality of the sensory experience, shapes the current perception of oneself, becoming an element of his or her identity. The memories are mediated by the tangible stuff - the flavour of the still remembered egg sandwich, cabbage stew, or dumplings - and this evokes and presentifies the past event weaving it into the autobiographical narrative of one's experience of loneliness, longing, abandonment, affection, but also of one's sense of security and belonging.

Memories of everyday food practices and their socioeconomic context - post-war hunger, dull country fare, food shortages, and communal resourcefulness in securing foodstuffs - belong to a collective memory that becomes incarnated in specific events from one's individual past; however, in describing them, it is mostly conventional narrative forms and socially preserved figures of remembering that are used. These memories are composed of cultural forms and are interactively brought to life in social situations. Although they refer to distinctive physical sensations, they are shaped through commonly shared frameworks of meaning which focus our attention on the culturally meaningful, thus defining and determining not only the event itself, but also one's memory of it. The memory of home-baked bread, or of dishes served by a caring grandmother, refers to authentic individual family stories, but is influenced by cultural patterns that attribute high value to recollections of family life, the myth of a happy childhood, of strong familial bonds and community cohesion. These are collective memories of times that have gone forever, where taste can be idealized by adapting to social norms of remembering. Therefore, Grandma's cuisine must be incomparable, homemade bread must be unique to emphasize the radical change and irreversibly lost pastoral world of tastes.

We can best observe the social formation of sensory memory when we examine how differently each generation remembers the flavours of food from the socialist era. The real world is experienced in different ways depending on the person's age, their individual sensitivity and alertness, whether they perceive certain matters as important or not. Generation-specific memories of the tastes of the socialist era 
reflect this difference. This dichotomy may be construed as essentially two separate cultural formations set within the broader context of the generational experience of evolving social changes. The world of sensations is a vital aspect of these memories, it is an embodied form of remembering the past, determining also present attitudes to it. Various cognitive categories are superimposed on the actual food memories from the socialist era, organizing how they are being recalled and evaluated.

The nostalgic recollections of the older generation are centred around the discourse of loss: nothing will ever taste the same as before. The PRL era constitutes a period when food had "real" taste. This authenticity relates to the feeling of belonging, agency, and the ability to identify with the social system. The recollections of the younger generation operate within opposing frameworks: the nostalgia of childhood memories of Grandma's cuisine on the one hand, and the unhealthy and dull cuisine of parents on the other. The image of old-time food stands in contrast to the notions of diversity, novelty, healthiness, etc., that are so valued today. The collectivism of the past is replaced with individualism, and the reluctance to be conspicuous - with the desire to stand out from the crowd. Thus, the memory of tastes and flavours from the bygone years is a determining factor in how individuals relate to the modern era: when the older people talk about the taste one cannot find today, or about modern times being devoid of flavour, they engage in a discourse of loss, with its inherent judgement on modernity. Conversely, the younger generation is critical of the traditional cuisine, judging it by modern standards as unexciting, dull, unsophisticated, and unhealthy. In doing so, the younger generation is identifying with the present era and the meanings, sensibilities, and value hierarchies it creates. These new meanings ascribed to various food styles go on to shape new types of sensory responsiveness, ones which also influence how one remembers the tastes of the past; tastes that were once popular but are now despised.

Embodied sensations are a means of validating the vision of the past through their subjective, intimate, and enduring nature, thus creating an evocative emotional image imbued with meanings. The category of taste, incorporated into the form of memory narration, relates not only to the defined tangible world and the physical sensations it incorporates, but also to a broader socio-cultural context that allows introspection into how memory is formatted through sensations, how it encompasses various meanings pertaining to culture and selfhood, and how it becomes a mechanism for interpreting the past and evaluating the present.

\section{LITERATURE}

\footnotetext{
A s s m a n n Jan 2008, Communicative and Cultural Memory, [in:] Cultural Memory Studies. An International and Interdisciplinary Handbook, eds. A. Erll, A. Nunning, Walter de Gruyter, Berlin-New York, pp. 109-118.

B o u r d i e u P i e r r e 1984, Distinction: A Social Critique of the Judgement of Taste, Harvard University Press, Cambridge.
} 
B rzostek Błażej 2010, PRL na widelcu, Baobab, Warszawa.

C a m p en van Creti en 2014, The Proust Effect. The Senses as Doorways to Lost Memories, Oxford University Press, Oxford.

C a ld we 11 Mel is s a L. 2004, Not by Bread Alone. Social Support in New Russia, California University Press, Berkeley Los Angeles London.

Clas s en C on st a n ce 1999, Other Ways to Wisdom: Learning through the Senses across Cultures, International Review of Education, Vol. 45, No. 3-4, pp. 269-280.

Classen Constan c e 2010, Foundations for an anthropology of the senses, International Social Science Journal, Vol. 49, No. 153, pp. 401-412.

C on ne r to n P a l 1989, How Societies Remember? Cambridge University Press, Cambridge.

D o m á ski He n ry k et al. 2015, Wzory jedzenia a struktura społeczna, Scholar, Warszawa.

Dunn Elis abeth C. 2008, Postsocialist spores: Disease, bodies, and the state in the Republic of Georgia, American Ethnologist, Vol. 35, No. 2, pp. 243-258.

Halbwa chs Maurice 1980, The Collective Memory, Harper \& Row Colophon Books, New York.

Hertzfeld Michael 1991, A Place in History. Social and Monumental Time in a Cretan Town, Princeton University Press, Princeton.

Herzfeld Mich a el 2011, „Senses”, [in:] Idem, Anthropology. Theoretical practice in culture and society, Wiley-Blackwell, New York-London, pp. 240-253.

Holtzman Jon D. 2006, Food and Memory, Annual Review of Anthropology, Vol.35, No. 1, pp. 361-378.

How es D a vid 2010, Sensual Relations: Engaging the Senses in Culture and Social Theory, University of Michigan Press, Ann Arbor.

How es D a vid 2013, The Expanding Field of Sensory Studies, Centre for Sensory Studies, Concordia University, Montreal, No. August, pp. 1-28.

Ko chan ow ski Jer z y 2010, Tylnymi drzwiami. Czarny rynek w Polsce 1944-1989, GW Foksal, Warszawa.

Kors meyer Carolyn, S ut t o n D avid 2011, The Sensory Experience of Food, Food, Culture and Society, Vol. 14, No. 4, pp. 461-475.

Ma n n h e i m Karl 1952, The Problem of Generations, [in:] Karl Mannheim Essays, ed. P. Kecskemeti, Routledge, pp. 276-322.

Nor a Pi erre 1996, Generations, [in:] Realms of Memory. Rethinking the French Past, ed. P. Nora, Vol. 1, Columbia University Press, New York.

Olick Jeffrey K. 1999, Collective memory. The two cultures, Sociological Theory, Vol. 3, No. 17, pp. 333-348.

Prager Jeffrey 1998, Presenting the Past: Psychoanalysis and the Sociology of Misremembering, Harvard University Press, Cambridge MA.

Ri es N a n c y 2009, Potato Ontology: Surviving Postsocialism in Russia, Cultural Antropology, Vol. 24, No. 2, pp. 181-212.

S e r e meta kis Na di a C. 1994, The Memory of the Senses, Part I: Marks of the Transitory, [in:] The Senses Still. Perception and Memory as Material Culture, ed. N. Seremetakis, Chicago University Press, Chicago.

Stań c zak-Wiślicz Kat a r zyn a 2014, Kryzysowe praktyki kulinarne w Polsce lat 80. XX wieku na łamach ówczesnej prasy kobiecej, [in:] Terytoria smaku, ed. U. Jarecka and A. Wieczorkiewicz, Wydawnictwo IFiS PAN, Warszawa, pp. 321-348.

S t o la t. . 2018, Sto lat Polski w liczbach 1918-2018, Główny Urząd Statystyczny, Warszawa.

Sutton David E. 2010, Food and the Senses, Annual Review of Anthropology, Vol.39, No.1, pp. 209-223.

Sutton David E. 2001, Remembrance of Repast: An Anthropology of Food and Memory, Berg Publishers, Oxford-New York. 
JUSTYNA STRACZUK

\author{
"I STILL REMEMBER THIS TASTE". \\ SENSES AND EMOTIONS IN PERCEIVING CULTURAL CHANGE
}

Keywords: Poland, memory of the senses, food memory, embodied memory, emotions, nostalgia, social change

This article focuses on the problem of food memories within the context of individual life stories and collective histories from post-war Poland. The category of taste understood as a sensory experience, a cultural code, and a social norm provides an insight into the ways in which senses evoke and format memory, and how they become a tool for interpreting the past and evaluating the present. Taste memory influences both personal accounts of individual life events, but also the collective memory of the past. This memory is distinct to each generation and offers differing evaluations of the past and approaches to social changes. While the memory of the older generation is nostalgic and set within the discourse of loss, the younger generation's memory is ambivalent, becoming either a mythical tale of a happy childhood or the means of criticizing the old and validating the present ways of life.

Author's Address:

Dr Justyna Straczuk

Institute of Philosophy and Sociology, Polish Academy of Sciences

Nowy Świat 72, 00-330 Warszawa

Email: justyna.straczuk@ifispan.edu.pl

ORCID: 0000-0001-6091-8786 